\title{
The Optimal Design of U-Turns on Thai Highways
}

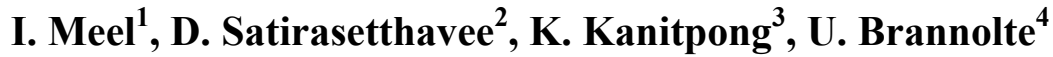 \\ ${ }^{1}$ EU-Asia Road Safety Centre of Excellence (RoSCoE) \\ Prince of Songkla University, Hat Yai 90112, Songkla, Thailand \\ E-mail: ipmeel@yahoo.co.in
}
${ }^{2}$ Department of Civil Engineering, Faculty of Engineering, Naresuan University E-mail: dussadee_s@outlook.com

\section{${ }^{3}$ School of Engineering and Technology, Asian Institute of Technology Pathumthani, Thailand, E-mail: kanitpon@ait.ac.th}
${ }^{4}$ Department of Transport Planning and Traffic Engineering, Faculty of Civil Engineering, Bauhaus-University Weimar, Marienstrasse 13C, 99423, Weimar, Germany, E-mail: ulrich.brannolte@uni-weimar.de

Abstract: The purpose of this study is to evaluate optimal layout design of U-turns on basis of road safety for highways of Thailand. In Thailand, U-turns are one of major segments of highways after intersections, contributing to rural highway crashes. Different layout designs of U-turn and variation in its elements are influencing factors for drivers' expectance and causing confusion in drivers. Therefore, the evaluation of layout designs of U-turn of rural highways is important to reduce future crash rates. For this research, initially the 'accident based investigation' was considered, the accident cost rates for different layout designs was planned to be evaluated. But due to underreporting of accident data in various agencies in Thailand, the 'accident based investigation' could not produce reliable results, so 'event based investigation' is considered for further study. For 'event based investigation' study the 'traffic conflict technique' is planned to use.

Keywords: U-turn, road-safety, traffic conflict technique

\section{Introduction}

\subsection{Background}

Road safety has received considerable attention all around the world. In order to get a better insight into the safety effects of present highway designs, the partner universities of the international scientific network "RoSCoE: EU-Asia road safety centre of excellence" have established to conduct research works on different segments of rural 
highways, such as intersections, U-turns, cross sections, rail-road crossings and grade separated junctions.

Other than intersections, highways can divided in U-turns (median opening), tangent sections and curved sections. U-turns on divided Thai highways are provided to avoid direct right turn from highway to minor roads, to avoid direct right turn from minor road to highways (for left hand traffic), to reduce travel time for emergency services, efficient law enforcement and for highway maintenance purposes. U-turns are classified based on geometric layout.

\subsection{Need for the present study}

Economic growth in Thailand has brought about an expanding network of roads and an increasing number of the driving public. The growing number of vehicles on the roads, in turn, has contributed to significant increases of road crashes annually. Road crashes have been a major cause of death and injury in Thailand. Traffic accidents are associated economic losses and social consequences. The economic costs include medical services, productivity losses, property damage, emergency services, insurance administration, premature funeral costs, vocational rehabilitation, legal expenses, etc. Annual economic losses in Thailand due to traffic crashes are account about 2 to 3 percent of the Gross Domestic Product (GDP) [1], [5]. Similar statistic of economic losses due to traffic crashes were estimated for Australia [4].

\subsection{Approach for the present study}

Accident cost rates can be related to the costs of possible improvement measures, so the road administration is able to identify the road sections where safety improvement measures are expected to have the best efficiency [2]. At the beginning, the aim of this research was to evaluate the optimal design of U-turn on divided rural highway in Thailand with respect to accident based investigation (based on accident cost rates). Accident can be categorized on basis of heaviest consequences (severity). Based on calculated accident cost rate for accident categories and classified U-turn, the optimal design could be evaluated. To evaluate accident cost rates, the reliability and quality of data are most important factors to achieve reliable result for an accident based research. There are limitations associated with research based on accidents, accidents are rare events and are therefore associated with the random variation inherent in small numbers, also not all accidents are reported and the level of reporting is unevenly distributed [3]. The Traffic Conflict Technique (TCT) can be considered as a surrogate or complementary methods in place of accident analysis.

A pilot study was conducted to investigate availability and assess quality of accident data for Department of Highways and Royal Thai Police; it has been found that road accident data are underreported in these agencies. Due to underreporting of accident data, it was not possible to continue this research with 'accident based investigation', so it is considered to continue study with 'event based investigation' on the basis of 'traffic conflict techniques'.

Traffic is interaction - all events in traffic contain some kind of interaction but of course to varying extent. There is interaction between road users and there is interaction 
between the road user and the road environment. Traffic conflict is defined as "A Conflict is an observational situation in which two or more road users approach each other in space and time to such an extent that a collision is imminent if their movements remain unchanged" [7]. A safety pyramid suggested by Hyden [7], as shown in Figure 1 [12].

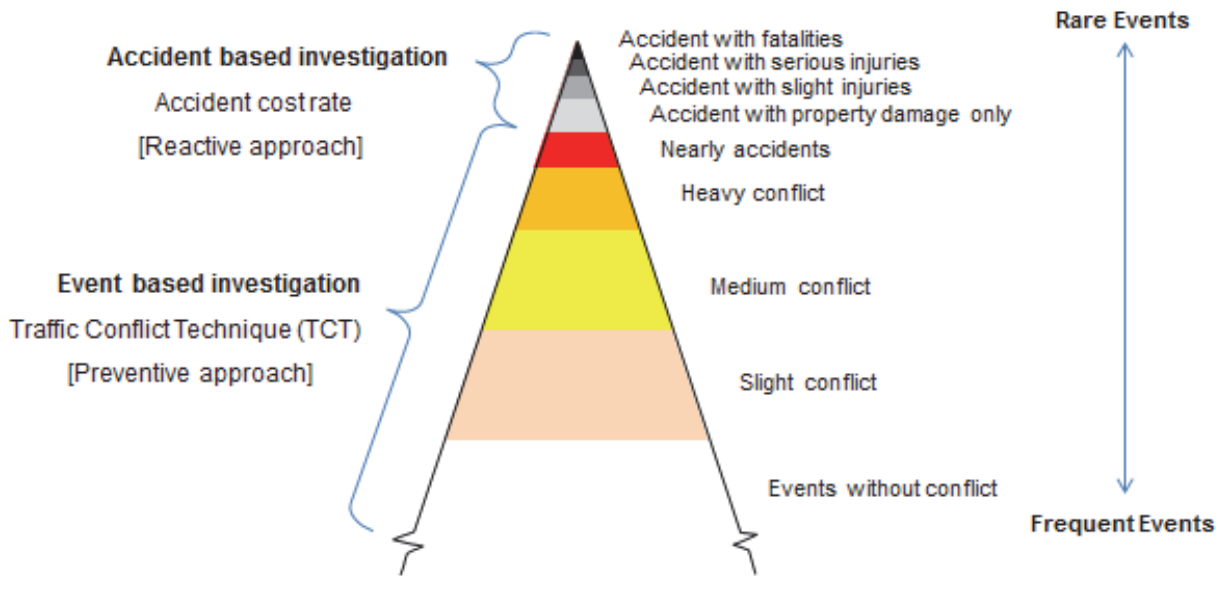

Figure 1. Traffic events with respect to time duration

The effect of various elements of U-turn on road safety can be evaluated with respect to rate of severity of conflicts. The expected outcome of this research will be selection of most appropriate geometric layout of U-turn to enhance highway safety and reduce economic losses to country causes by traffic crashes.

To study road safety aspects on U-turn, its layout designs elements (auxiliary lanes and loon), access control, approach speed, turning vehicle percentage and heavy vehicle percentage are major parameters considered for this research.

\subsection{Objectives of the study}

The main objectives of the present study are:

1. To assess possibility to evaluate 'accident cost rate' of different 'accident category' on various U-turn layout design practices on rural highways of Thailand,

2. To analyse availability and quality of accident data recorded in various agencies (Department of Highways and Royal Thai Police) for rural highways in Thailand,

3. To evaluate the effect variation of U-turn elements (median opening length, auxiliary lanes, loon etc.) on severity based conflict rate with respect to traffic exposure.

4. To assess most appropriate layout design of U-turn for divided highways of Thailand with respect to traffic exposure and traffic conflict events (Traffic Conflict Technique). 


\section{Pilot study for accident based investigations}

\subsection{Aim of the pilot study}

A pilot study was conducted to assess the availability and quality of accident data with accident reporting agencies (Department of Highways and Royal Thai Police) in Thailand.

\subsection{Scale of the pilot study}

Total 35 U-turns locations around Hat Yai were identified for pilot study. Accident data information was collected from 8 responsible Royal Thai Police stations for identified U-turns. Accident data from Department of Highways were also collected and analysed.

\subsection{Outcome of the pilot study}

There is a serious underreporting with the Department of Highways $(\mathrm{DoH})$ data because $\mathrm{DoH}$ only reports accidents if there is damage to property of $\mathrm{DoH}$.

The Royal Thai Police accident reports are unstructured; these reports don't have data of exact location identification of accidents, so it was not possible to identify accidents in these reports for selected U-turns for Pilot study. Also accident reports are prepared in descriptive format (in Thai language) and are manually written (no softcopy available), a number of reports were written in poor handwriting. Some police stations didn't permit to take photo or photo-copy of accident reports. So accident data of Royal Thai Police are not suitable for this study.

An earlier study also indicated about incomplete accident data, no data sharing between agencies in Thailand, the Department of Highways having about $60 \%$ underreporting as comparing to Royal Thai Police [8]. Due to these limitations it was not possible to carry on this research study based on accident based investigations.

\section{Event based investigation}

\subsection{Traffic conflict technique and limitations}

Traffic conflict techniques are considered as surrogate approach to accident based investigations [9]. The basic hypothesis is that there is a close relationship between conflicts and accidents [3]. Broadly traffic conflict technique classified as 'subjective approach' and 'objective approach' [10]. Subjective methods include considerable judgment of evasive action of road user by the conflict observer. Objective method use Time-space criteria such as Post Encroachment Time (PET) and Time to Collision (TTC). Objective approach requires sophisticated video recording locations and video analysis (image processing) software/ equipment. For this study, there are unavailability of structures near to identified U-turns to fix camera to capture a bird's-eye view (elevated view), as selected U-turns are in non-built up areas and rows of trees along the highway hinder to capture movement of vehicles from transverse direction. Due to these constraints it is planned to conduct further research based on subjective approach of traffic conflict technique. 
Table 1 and table 2 are showing requirements and features of subjective and objective approaches of Traffic Conflict Techniques.

Table 1. Requirements TCT approaches

\begin{tabular}{|l|l|}
\hline \multicolumn{1}{|c|}{ Subjective Approach } & \multicolumn{1}{c|}{ Objective Approach } \\
\hline $\begin{array}{l}\text { Require trained technical } \\
\text { observers }\end{array}$ & $\begin{array}{l}\text { Require sophisticated positions of video cameras for } \\
\text { recording and image processing computer programs }\end{array}$ \\
\hline $\begin{array}{l}\text { Require shorter time } \\
\text { period for investigation }\end{array}$ & Require longer time period for investigation \\
\hline
\end{tabular}

Table 2. Features of TCT approaches

\begin{tabular}{|c|l|}
\hline Subjective Approach & Objective Approach \\
\hline Surrogate to objective approach & Surrogate to accident based investigation \\
\hline
\end{tabular}

\subsection{Elements, Classification and Zones of U-turns}

\subsubsection{Elements of U-turns}

U-turns are combinations of various elements such as (1) through lanes, (2) deceleration lane, (3) median opening width, (4) acceleration lane, (5) median width at opening, (6) outer widening / loon and (7) directional island as show in Figure 2.
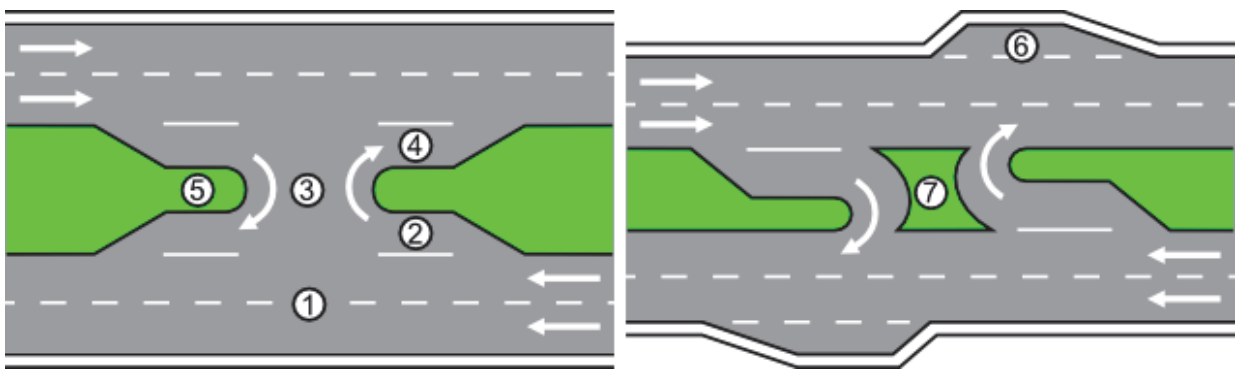

Figure 2. Elements of U-turns

\subsubsection{Classification of U-turns}

In Thailand various geometric design practices of U-turns are adopted. On the basis of combination of various elements, U-turns in Thailand are classified as following (Figures 3 to 6 ).

- UT-1: Conventional without auxiliary lanes,

- UT-2: Conventional with deceleration lanes,

- UT-3: Conventional with auxiliary lanes (acceleration and deceleration),

- UT-4: Directional with auxiliary lanes (acceleration and deceleration),

- UT-5: Conventional with deceleration lane and triangle shape outer widening,

- UT-6: Conventional with auxiliary lanes (acceleration. and deceleration) \& triangle shape outer widening,

- UT-7: Conventional with deceleration lane and outer widening for upstream and downstream, and

- UT-8: Conventional with deceleration lane and loon. 


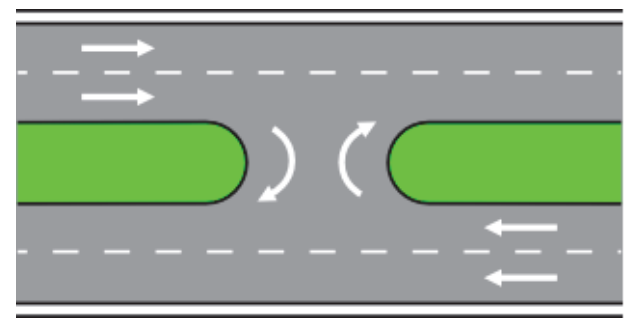

(a) UT-1

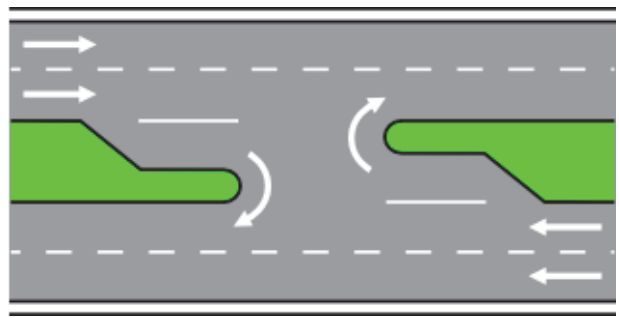

(b) $U T-2$

Figure 3. U-turns in Thailand

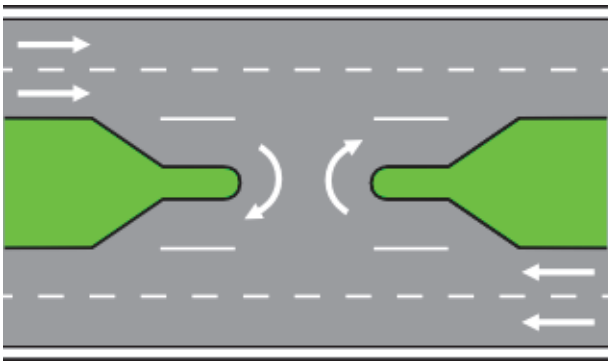

(a) UT-3

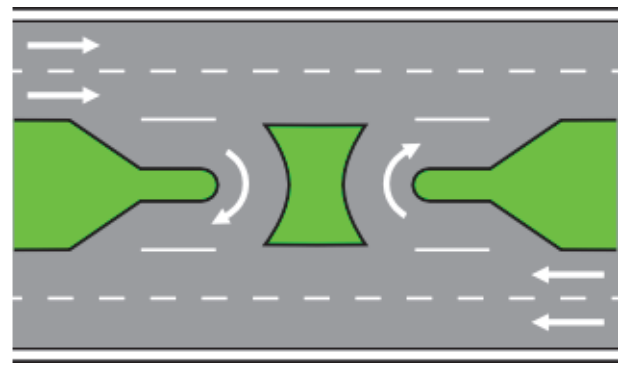

(b) $U T-4$

Figure 4. U-turns in Thailand

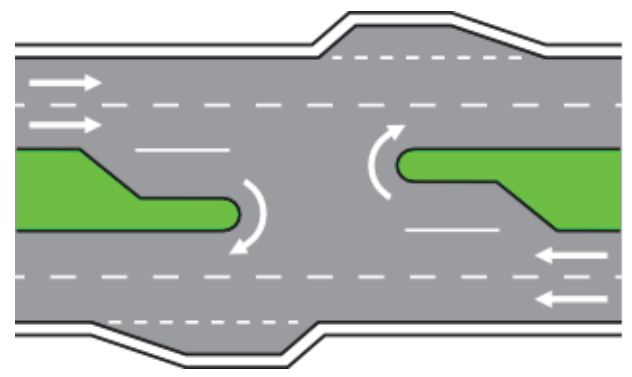

(a) UT-1

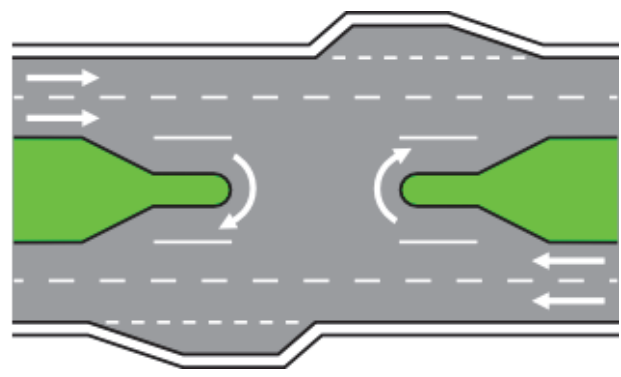

(b) UT-2

Figure 5. U-turns in Thailand 


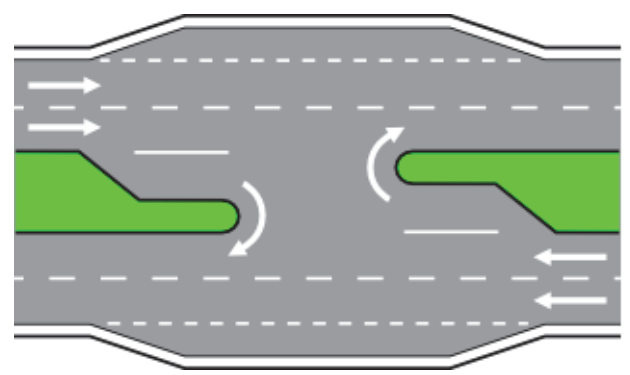

(a) UT-7

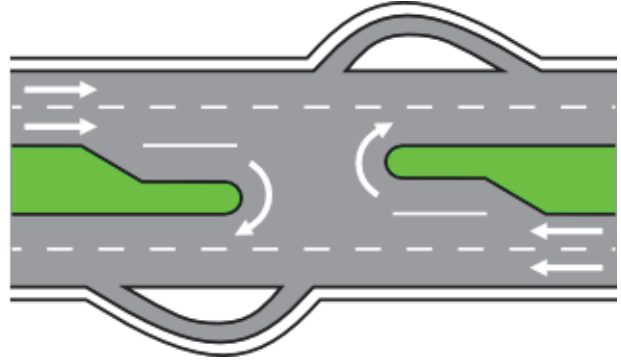

(b) $U T-8$

Figure 6. U-turns in Thailand

A similar classification based on U-turn elements was published in an earlier study [6]. Also, it was found that a directional island improves safety at U-turn and Provision of loons along four-lane arterials to accommodate U-turn maneuvers by trucks should be considered while designing [6]. Consistency needs to be maintained with relation to the design of loons and placement of crossovers along narrow medians [11].

\subsubsection{U-turn zones}

For a U-turn manoeuvre, a road user has to follow three actions, first he has to decelerate and divert from through traffic, second he has to make a turning manoeuvre, and third he has to accelerate and merge in through traffic. For this study, U-turns are divided in three zones as following (Figures 7 and 8).

- Zone 1: Upstream zone (for deceleration and diverging),

- Zone 2: Turning zone (for turning movement) and

- Zone 3: Downstream zone (for acceleration and merging).

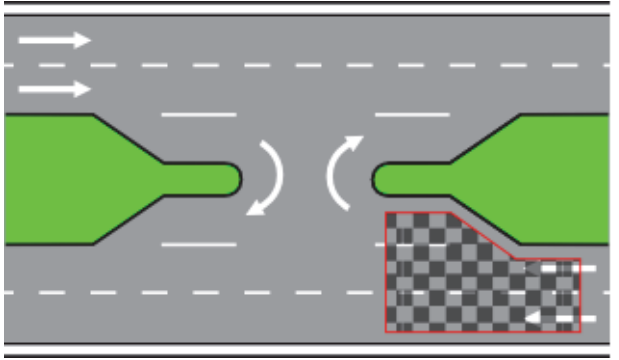

(a) Zone 1

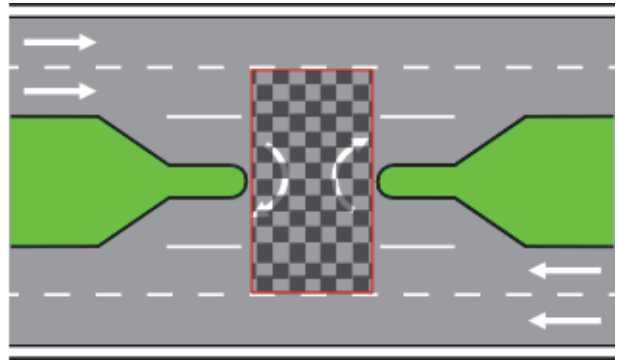

(b) Zone 2

Figure 7. U-turn zones 


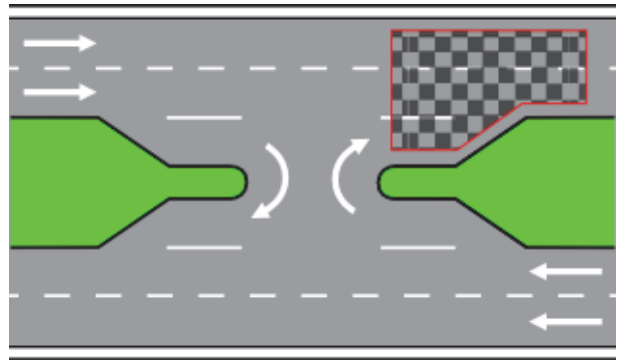

Figure 8. U-turn Zone 3

The number of through lanes and the length of deceleration lane are the variable elements for the upstream zone. In the turning zone the variable elements are median width, width of median opening and presence of Directional Island. For downstream zone the variable elements are the number of through lanes, length of acceleration lane adjacent to median and, layout design and width of outer widening or loon.

\subsection{Traffic interactions events}

Four types of Traffic Interaction Events are considered for this study.

- Traffic Interaction without interference: A situation in which two or more road users approach each other in space and time without interfering each other's speed and manoeuvres.

- Traffic Interaction with interference: A situation in which two or more road users approach each other in space and time with interfering each other's speed and/or manoeuvres up to an accepted level (i.e. without any evasive action by any road user).

- Traffic Conflict (Interaction with heavily interference): A situation in which two or more road users approach each other in space and time to such an extent where one or both drivers take evasive action to avoid a collision.

- Traffic Accident: A situation in which two or more road users approach each other in space and time to such an extent where their vehicles collide even evasive action is taken by one or both drivers.

\subsection{Classification of conflicts for U-turns}

Based on the three zones, the different possible conflicts are classified as follows.

\subsubsection{For Upstream Zone}

1. UC-1 (U-turn and/or Through, Same-Direction): Occurs when the first vehicle slows to make a U-turn, thus placing a second vehicle in danger of a rear-end or sideswipe collision.

2. UC-2 (U-turn and Through, Same-Direction, Secondary Conflict): Occurs when a second (through) vehicle makes a manoeuvre to avoid the first vehicle (U-turn), placing a third vehicle in danger of a collision.

3. UC-3 (Deceleration lane overflow): Occurs when U-turn vehicles storage overflow the deceleration lane and block a through lane.

4. UC-4 (Other conflict type): Conflict that cannot be assigned to the types $1-3$. 


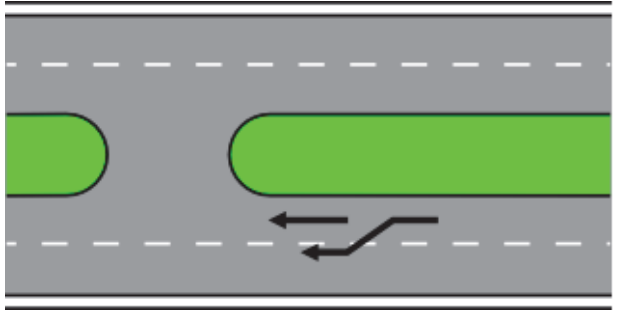

(a) UC-1

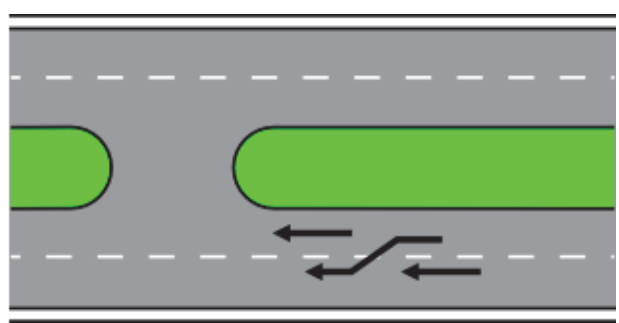

(b) $U C-2$

Figure 9. Upstream zones

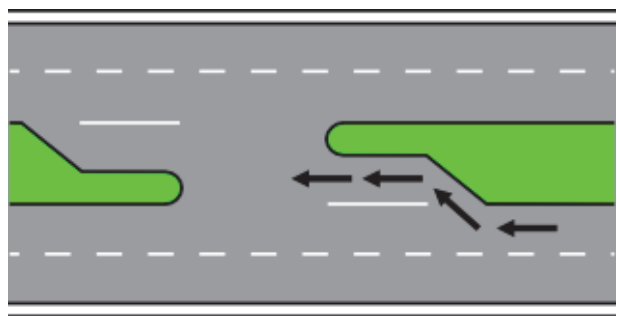

Figure 10. Upstream Zone UC-3

\subsubsection{For Turning Zone}

1. TC-1 (U-turn, Same-Direction Conflict): Occurs when the first vehicle slows/stops while U-turning, thus placing a second following vehicle in danger of a rear-end collision.

2. TC-2 (U-turn, Opposite-Direction Conflict): Occurs when vehicles from opposite directions make U-turn such that placing in danger both vehicles of head-on or sideswipe collision.

3. TC-3 (Opposing U-turn and Through Conflict): Occurs when an opposing stream vehicle makes a U-turn, placing a second vehicle in danger of a head-on or broadside collision. Here the second vehicle has the right-of-way.

4. TC-4 (U-turn manoeuvre not from adjacent lane to median, same direction Conflict): Occurs when the first vehicle, from other then adjacent lane to median makes a U-turn, thus placing a following second vehicle in danger of a rear-end or a sideswipe collision.

5. TC-5 (Other conflict type): Conflict that cannot be assigned to the types $1-4$.

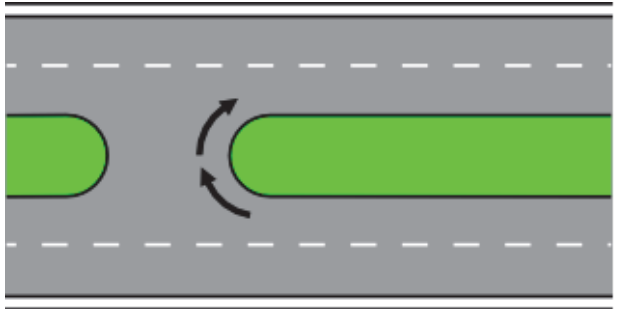

(a) $T C-1$

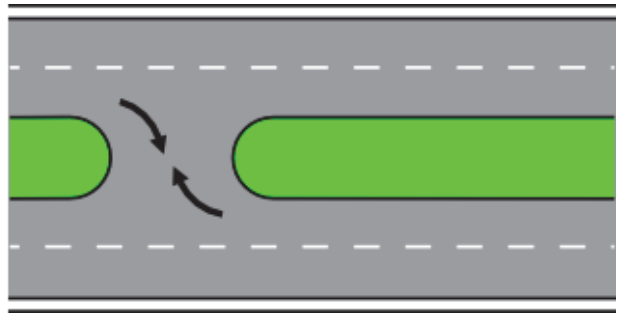

(b) $T C-2$

Figure 11. Turning zones 


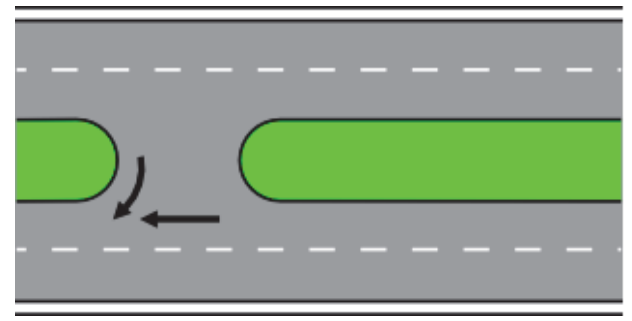

(a) TC-3

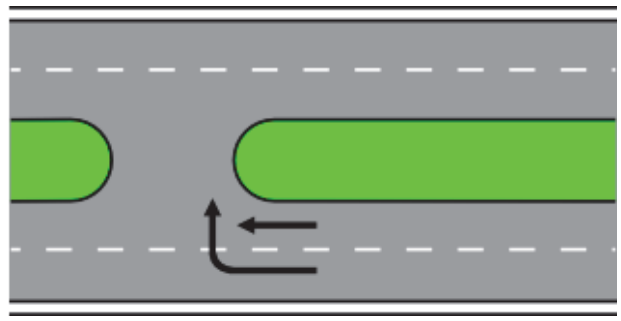

(b) $T C-4$

Figure 12. Turning zones

\subsubsection{For Downstream Zone}

1. DC-1 (Lane change Conflict): Occurs when the first vehicle changes lane from auxiliary (acceleration) lane to a through lane, thus placing a through second vehicle in danger of a rear-end or a sideswipe collision.

2. DC-2 (Secondary Conflict): Occurs when a second (through) vehicle makes a manoeuvre to avoid the first vehicle (lane changes from acceleration to through), placing a third vehicle in danger of a collision.

3. DC-3 (Other conflict type): Conflict that cannot be assigned to the types $1-2$.

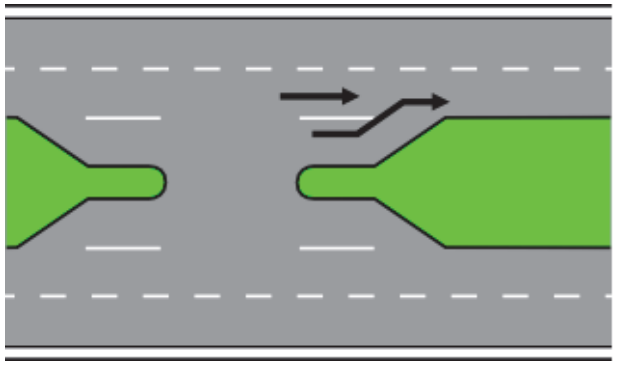

(a) $D C-1$

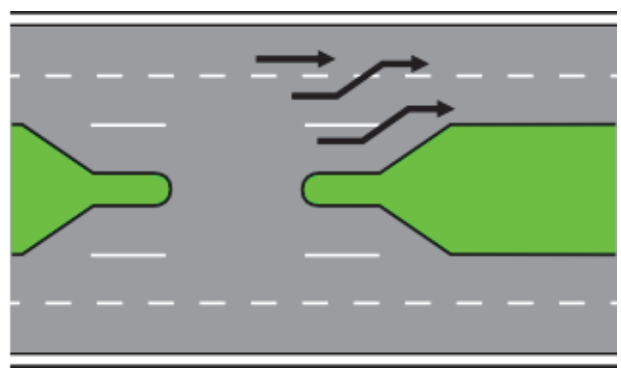

(b) $D C-2$

Figure 13. Downstream zones

\subsection{Severity of traffic conflict events and indicators}

Three types of conflict severities are considered for this study.

1. Slight traffic conflict event: A situation where one or more road user use "sudden brake" to avoid collision at a traffic conflict situation.

2. Moderate traffic conflict event: A situation where one or more road user "apply sudden brake and stop" to avoid collision at a traffic conflict situation.

3. Severe traffic conflict event: A situation where one or more road user use "hard brake" resulting braking sound or skid marks on the road surface to avoid collision at a traffic conflict situation. 


\subsection{Data collection}

For 8 types of classified U-turns, it was decided to collect data on 2 U-turns of each type for 2 peak hours and 2 non-peak hours for both sides of traffic streams. For this study the following data are planned to be collected.

\subsubsection{Traffic exposure}

- Through traffic volume,

- U-turning vehicle volume,

- Traffic composition (percentage of heavy vehicles with respect to the total number of vehicles),

- Approach speed,

\subsubsection{Geometric layout data of U-turns}

For this research purpose, the following geometric layout data of U-turns will be collected:

- Number of through lanes,

- Length of deceleration lanes,

- Width of median opening,

- Length of acceleration lanes,

- Median width at U-turn,

- Dimensions of outer widening or loon, and

- Type and dimensions of directional island

\subsubsection{Traffic conflict data}

For this research purpose, based on severity of conflict, the following conflict data will be collected and video recorded:

- Slight traffic conflict: "sudden brake" action,

- Moderate traffic conflict: "sudden brake and stop" action,

- Severe traffic conflict: "hard brake" causing braking sound or skid marks.

\subsection{Data analysis and expected results}

Traffic exposure data, conflict data and geometric data of U-turns will be analysed to assess the safest U-turn layout designs for various traffic conditions. The expected outcome of data analysis is as following:

- A relationship between severities based conflict rates with various U-turns elements (auxiliary lanes, directional island etc.).

- A relationship between severities based conflict rates with percentage of turning vehicles.

- A relationship between severities based conflict rates with traffic composition. 


\section{Conclusions}

The outcome of the pilot survey indicates that accident data of Royal Thai Police and Thai Department of Highways are underreported and not reliable for accident based investigations. So it was not practicable to continue this research work on the basis of accident based approach, therefore it was decided to use another surrogate approach of 'event based investigation'. Traffic conflict technique (TCT) is considered for further investigation.

\section{References}

[1] Luathep, P., Tanaboriboon, Y.: Determination of Economic Losses due to Road Crashes in Thailand, Journal of the Eastern Asia Society for Transportation Studies, vol. 6, pp. 3413-3425, 2005

[2] Steinbrecher, J., Schubert, T.: Safety of rural roads in Germany, 12th WCTR, July 11-15, Lisbon, Portugal, 2010

[3] Svensson, A.: A Method for Analysing the Traffic Process in a Safety Perspective. Bulletin 166, Department of Traffic Planning and Engineering, Lund University, Sweden, 1998

[4] Connelly, L.B., Supangan, R.: The economic costs of road traffic crashes: Australia, states and territories, Accident Analysis \& Prevention, vol. 38, pp. 1087-1093, 2006

[5] Thongchim, P., Taneerananon, P., Luathep, P., Prapongsena, P.: Traffic accident costing for Thailand, Journal of the Eastern Asia Society for Transportation Studies, vol. 7, pp. 2891-2906, 2007

[6] Potts, I., Harwood, D., Gluck, J., Levinson, H.: Safety of U-turns at Unsignalized Median Openings on Urban and Suburban Arterials, National Cooperative Highway Research Program Report 524, 2005

[7] Amundsen, F.H., Hydén, C. (ed.): Proceedings: First workshop on traffic conflicts. TØI Oslo/LTH Lund, ISBN 82-7133-195-7, 1977

[8] Srirat, P.: Under-Reporting of road casualty accident data: a case study of highways in Nakhon Ratchasima, Thailand, Master Thesis, Asian Institute of Technology, School of Civil Engineering, Thailand, 2008

[9] Tarko, A., Davis, G., Saunier, N., Sayed, T., Washington, S.: Surrogate Measures of Safety ANB20(3), Subcommittee on Surrogate Measures of Safety ANB20 Committee on Safety Data Evaluation and Analysis Contributors, White Paper, 2009

[10] Shinar, D.: The Traffic Conflict Technique: A Subjective vs. Objective Approach, Journal of Safety Research, vol. 15, pp. 153-157, 1984

[11] Sisiopiku, V., Aylsworth-Bonzelet, L.: Application of Loons at Directional Crossovers, Presented at the 82nd annual meeting of Transportation Research Board, Washington, D.C., 2003

[12] Chin, H. C., Quek, S. T.: Measurement of Traffic Conflicts, Safety Science, vol. 26, no. 3, pp. 169-185, 1997 